\title{
humanidades
}

Revista humanidades

Diciembre, $2014 \bullet$ Volumen 4 •ISSN 2215-3934・pp. 1-51

\section{La loca Đ El gado: Un análisis de la figura del héroe de la novela El gato de sí mismo, de Uriel Quesada}

DOI: http://dx.doi.org/10.15517/h.v4i1.16318

Recibido: 23-Enero-2014 / Aceptado: 29-Mayo-2014

\section{José Pablo Rojas González}

Máster, profesor Interino en la Sección de Comunicación y Lenguaje de la

Escuela de Estudios Generales de la Universidad de Costa Rica

Correo electrónico: jprojasg@gmail.com 


\section{La loca Đ El gado: Un análisis de la figura del héroe de la novela El gato de sí mismo, de Uriel Quesada}

\section{Resumen}

El presente trabajo busca estudiar -a partir de los aportes teóricos de Mijaíl Bajtín- la figura del héroe de la novela $E l$ gato de sí mismo de Uriel Quesada. Se pretende caracterizar al héroe de este texto costarricense como una nueva variante del "soñador" y del "hombre del subsuelo" bajtinianos. Esta caracterización permitirá señalar la importancia de atentar contra el estereotipo, de atentar contra el «orden sexual» establecido, a favor-siempre- de la libertad del ser humano.

\section{La loca $Ð$ El Gado: An analysis of the figure of the hero in the novel El gato de sí mismo, by Uriel Quesada}

\section{Abstract}

This paper studies the figure of the hero in Uriel Quesada's novel, El gato de sí mismo. The main character of this Costa Rican novel is presented as a new variant of both the "dreamer" Keywords: Costa Rican novel, bakhtinian hero, dreamer, underground man. and the "underground man". These two notions - explained by Mikhail Bakhtin- are central in this work, because they will stress the importance of both attacking the stereotype and undermining the «established sexual order», to reinforce the value of freedom. 
El gato de sí mismo es una novela que logra visibilizar a uno de los «sujetos» más olvidados o-dicho con mayor propiedad-más ocultados de nuestras sociedades: el gay ${ }^{1}$. Este texto, por lo anterior, se puede definir como un texto literario «revolucionario», en el sentido en que muestra una realidad que ha sido, intencionalmente, relegada a la oscuridad. El gato de sí mismo, sin embargo, no se queda ahí, no se queda en la mera mostración. Esta novela también logra minar (como se tratará de demostrar) los planteamientos tradicionales que buscan definir a los sujetos ${ }^{2}$. La novela de Quesada es una novela que aboga por la libertad del ser humano como una condición fundamental para la resubjetivación; es decir, para lograr el cambio que lleva de la sujeción a la reinvención de uno mismo. La noción de resubjetivación es, de hecho, central para entender al protagonista de esta novela (Germán Germanóvich), un protagonista que hace uso de la narración, hace uso de la libertad que le ofrece su "fantasía", con el fin de «recrearse» y, claro, de huir de los poderes que buscan definirlo, pensarlo y, finalmente, hablarlo.

Lo mencionado sobre el narrador-protagonista de esta novela está en profunda armonía con lo que Mijaíl Bajtín apunta sobre el héroe de la novela polifónica. Bajtín, en efecto, aclara la importancia de la novela polifónica a partir de esa actitud de ceder la palabra a los héroes, a lo que, además, hay que agregar la riqueza de una novedosa visión artística del mundo, en la que lo heterogéneo reina sobre lo homogéneo, en la que todos tienen cabida y, sobre todo, voluntad. El teórico ruso define a los héroes de la novela

\section{A manera de introducción}


polifónica con dos nociones básicas: la de "soñador" y la de "hombre del subsuelo". Ambas están ligadas y, como se verá, las dos caracterizan al héroe de la novela costarricense propuesta. Según Bajtín, el "soñador" es un héroe que quiere y no puede materializar su ilusión. El "hombre del subsuelo", por su parte, es un héroe que destruye todos sus rasgos firmes, es un sujeto de la conciencia y el sueño, caracterizado por su inconclusión.

Estas nociones, entonces, serán relevantes para analizar a un héroe como Germán Germanóvich, en la medida en que, como se verá, le permiten «ser», le permiten decirse en su diferencia y, con ello, atentar contra el «orden sexual» establecido. Germán Germanóvich es un gay y, como tal, está relegado al ámbito de lo "irreal”, dentro del «orden patriarcal». Minar este «orden» es, por tanto, una cuestión crucial en pro de los «sujetos» gays (y, en general, en pro de todos los «sujetos» inferiorizados por este sistema opresor), así como es determinante alterar las instituciones que (re)producen dicho «orden» ${ }^{4}$. La «exposición espectacular»-que se verá en El gato de sí mismobusca, precisamente, eso: busca acabar con la inferioridad y la vulnerabilidad de los gays, como con los medios de control que se ejercen sobre estos «sujetos», a los que -como afirma Eribon- les es fundamental poder dar sus propias representaciones ${ }^{5}$. 
Precisamente, El gato de sí mismo viene a plantear una novedosa representación de las subjetividades gays: Germán Germanóvich es, en esta novela, un artista del performance (en el sentido que tiene esta palabra en inglés ${ }^{6}$. Él, a través de su autobiografía ${ }^{7}$ y en un acto consciente, se propone tomar la palabra para reinventarse en su calidad de "paria", con el claro fin de eludir cualquier predeterminación y, entonces, acentuar la multiplicidad y la pluralidad. Germán Germanóvich, el héroe de esta novela, es «su propia obra de arte» (esta expresión es de Foucault).

Como se tratará de comprobar, el trabajo literario de Germán es, ante todo, un medio para reinventar su vida, para modificar la acción de la historia -de su historia personal- y, con ello, darse un nuevo significado, pero desde la heroificación ${ }^{8}$. La heroificación -como se verá- le es fundamental para transformarse en «obra de arte» por medio de la escritura. Este trabajo consciente del narrador-protagonista, entonces, permitirá desvincular a Germán Germanóvich (y a la novela misma) de cualquier rasgo asociado a la locura (específicamente a la esquizofrenia ${ }^{9}$ ). De hecho, uno de los objetivos principales de este trabajo será entender este texto no como una forma de representación de cierta "locura vacía" -sin sentido- en el narradorprotagonista sino como la representación de la conciencia de un «sujeto» pleno. Calificar a Germán Germanóvich como un esquizofrénico (o, más aún, hablar de esta novela como la novela de un viaje a través de la enfermedad mental), no es sino patentizar una representación homófoba de profunda raigambre dentro del discurso heterocentrista ${ }^{10}$. 
El gato de sí mismo, a pesar de haber ganado el Premio Nacional Aquileo J. Echeverría de Novela en el año 2005, es una novela desconocida, una novela de la que no se habla desde entonces, incluso dentro de la Academia. El premio parece haberla entregado al olvido, parece haberla ocultado... Contra esta actitud es que surge este trabajo, que se puede definir, también, como una mostración. Se busca, aquí, descubrir un texto que puede activar una reflexión sobre los diferentes aspectos de la sexualidad humana, una reflexión que despliegue nuevas posibilidades de análisis en torno a las identidades de los «sujetos». Eribon lo plantea en los siguientes términos:

$\mathrm{Si}$, como insiste toda la obra de Foucault, al menos el primer Foucault, una sociedad se define por lo que hay en ella de decible y pensable, puede afirmarse que la visibilidad gay y lesbiana ha tenido por efecto transformar la sociedad en su conjunto, ya que ha modificado profundamente lo que es posible decir, lo que se puede ver y, por consiguiente, pensar. La movilización homosexual, la salida a la luz del día y la intensificación de la vida «subcultural» representan sin duda (junto con el feminismo) uno de los mayores entredichos en que ha sido puesto el orden establecido, sexual y social, pero asimismo «epistemológico», del mundo contemporáneo (Eribon, 2001, p. 48).

Lo anterior evidencia, entonces, la relevancia de un trabajo como el propuesto, en el que finalmente se busca entender la novela de Quesada sobre todo a partir de la crisis que puede (y debe) provocar: su riqueza está en 
«revolucionar» no solo el lenguaje literario sino, asimismo, la noción cerrada de «sujeto», en un gesto político que se opone a la violencia que implica la norma patriarcal heterocentrista.

Nos parece que se puede hablar directamente acerca del pensamiento artístico polifónico que traspasa los límites del género novelesco. Este tipo de pensamiento es capaz de alcanzar tales aspectos del hombre -

\section{El héroe en la novela polifónica} ante todo, la conciencia pensante del hombre y la esfera dialógica de su existencia-, que no son abarcables artísticamente desde una posición monológica (Bajtín, 2003, p. 395).

La novela, a partir de las aportaciones de Mijaíl Bajtín, solo puede caracterizarse como un género multifacético, siempre en proceso de formación. Esta particularidad es la que, en efecto, enriquece a este género que, finalmente, se puede definir como «sospechoso», en el sentido en que presenta en sí una gran diversidad de otros géneros, los cuales no permiten su definición o, mejor, establecen su indefinición. Por lo anterior, es importante, en este punto, trabajar algunas nociones básicas en torno a lo planteado por Bajtín sobre la novela polifónica, para, así, tener un punto de partida para el análisis que ahora se quiere llevar a cabo en torno a la novela de Uriel Quesada. 
Bajtín, en su trabajo Problemas de la poética de Dostoievski, desde su estado de la cuestión, expone las características que hacen singular a la novela de este autor. Explica, así, cómo ésta se distingue por una "auténtica polifonía de voces autónomas" (Bajtín, 2003, p. 15). La polifonía hay que entenderla como esa característica que, en los textos literarios, conjunta diversas conciencias independientes, que resultan en un trabajo de subjetivación de los héroes mismos de este tipo de textos. Afirma Bajtín: "Los héroes principales de Dostoievski, efectivamente, son, según la misma intención artística del autor, no sólo objetos de su discurso, sino sujetos de dicho discurso con significado directo" (Bajtín, 2003, p. 15) (Resaltado del autor). La polifonía bajtiniana se opone, entonces, a la existencia de un «yo» individual; así, el «sujeto» no puede ser más que un «sujeto» plural, en el sentido en que está atravesado por el lenguaje: los sujetos interactúan con muchas otras voces ajenas, muchos otros discursos que han asimilado y que se activan en el momento mismo en el que se habla.

Bajtín explica que todos los elementos de la estructura novelesca en Dostoievski son singulares (en relación, claro, con las novelas de tipo monológico), singulares porque están determinados por “[...] la tarea de formar un mundo polifónico y de destruir las formas establecidas de la novela europea, en su mayoría monológica (homófona)" (Bajtín, 2003, p. 16). Este teórico afirma que, desde el punto de vista de la novela monológica (y su correspondiente comprensión del mundo representado), el mundo en los 
textos polifónicos puede parecer desordenado y la estructura de ellos puede parecer un conjunto de elementos diversos e incompatibles. Sin embargo, con un análisis de la finalidad artística de estos textos, pueden explicarse esas "alteraciones" para comprender la coherencia de estas características.

Precisamente, esto es lo que ahora se pretende lograr con El gato de sí mismo, de Uriel Quesada: estudiar su especial textualidad, para así poder aprehender esta novela de la manera más orgánica posible, entendiéndola no como un texto "esquizofrénico" (como lo define Albino Chacón en la contraportada de la novela), sino como uno que se regodea en sus múltiples posibilidades estéticas. Es, entonces, relevante anotar desde ya lo que Bajtín señala para el caso de Dostoievski (lo hace a partir de unas afirmaciones del crítico Viacheslav Ivanov): este tipo de novelas no se quedan en un puro principio de estructuración literaria concreto sino que plantean una visión artística del mundo. El género novela mismo se conforma como «una totalidad artística verbal», como se tratará de demostrar aquí a partir del texto de Quesada.

La novela polifónica es, desde la teoría bajtiniana, aquella que conjunta los elementos más dispares para distribuirlos entre varios mundos y varias conciencias con los mismos derechos: “[...] no se dan en un mismo horizonte sino en varios, completos y equitativos, y no es el material inmediato sino estos mundos, estas conciencias con sus horizontes, los que se combinan en 
una unidad suprema, es decir, en la unidad de la novela polifónica" (Bajtín, 2003, p. 29). La clave artística de la novela polifónica está, entonces, en la relación entre el principio estructural -"unión de elementos heterogéneos e incompatibles"- con "la pluralidad de centros no reducidos a un común denominador ideológico" (Bajtín, 2003, p. 31). Evidentemente, contrario a la novela monogal, la novela polifónica conjunta lo disímil (con todas las contradicciones que esto implique), pero para justificar los puntos de vista más discordantes, para darles una base en el texto-novela mismo. La novela polifónica, en este sentido, es novela humana, ya que admite lo heterogéneo y lo contradictorio, rasgos que no sólo se dan en la estructura del texto, sino, también, en la misma intención artística. Afirma Bajtín: “[...] la voluntad artística de la polifonía es voluntad por combinar muchas voluntades, es voluntad del acontecimiento" (Bajtín, 2003, p. 38).

Coexistencia e interacción son las dos principales características de la visión artística que Bajtín señala en Dostoievski y que, por ende, se pueden extender al trabajo realizado en la novela polifónica en general. Estas se explican por esa necesidad de organizar, dentro de un solo tiempo, todo el material semántico y real, como apunta Bajtín. Lo anterior es importante tenerlo en cuenta en la medida en que el material textual y discursivo de la novela polifónica se presenta como "todo junto y simultáneo", y son precisamente estas características las que permiten entender este tipo de textos como textos dinámicos, que se mueven en el espacio y en el tiempo, y que llevan a sus 
héroes a vivir en el aquí y en el ahora. Afirma Bajtín: “[...] sus héroes no recuerdan nada, no tienen biografía en el sentido de algo pasado y totalmente agotado. Recuerdan de su pasado sólo aquello que no deja de ser para ellos el presente y que se vive por ellos como tal [...]" (Bajtín, 2003, p. 49). Y sigue: "Cada acto del héroe se encuentra completamente en el presente y en este sentido no está predeterminado; se piensa y se representa por el autor como un acto libre" (Bajtín, 2003, p. 50).

Como explica el teórico ruso, la estructura de la novela polifónica es la que, en sí misma, permite la representación de un mundo con una coexistencia y una integración artísticamente organizadas, lo que -desde la perspectiva de la novela monológica- se entiende, más bien, como caóticas. En estos textos afirma el teórico ruso- hay una heterogeneidad espiritual, no hay un proceso de formación, no se presentan las etapas del desarrollo de un espíritu único.

Lo anterior solo es posible entenderlo en relación con el concepto de “conciencia” que, según Bajtín, Dostoievski desarrolla siempre a partir del vínculo con la otredad; es decir:

La conciencia en Dostoievski nunca es autosuficiente sino que se vincula intensamente a otra. Cada vivencia, cada pensamiento del héroe son internamente dialógicos, polémicamente matizados, resistentes o, por el contrario, abiertos a la influencia ajena, y en todo caso no se 
concentran simplemente en su objeto sino que se orientan siempre al otro hombre (Bajtín, 2003, p. 50).

En efecto, lo importante es la interacción y la interdependencia. Lo vital en la polifonía, bien lo destaca el teórico ruso, consiste en el hecho de que todo tiene lugar entre conciencias diversas. Esto no hay que desligarlo de la estructura de la novela polifónica misma, que Bajtín entiende como enteramente dialógica; es decir, configurada con base en «el contrapunto artístico». Este autor lo explica de la siguiente manera: "Son varias voces que cantan de manera diferente un mismo tema. Ésta es, precisamente, la polifonía que descubre el carácter polifacético de la vida y la complejidad de las vivencias humanas" (Bajtín, 2003, p. 70) (Resaltado del autor).

[...] todo en la vida es diálogo, es decir, una contraposición dialógica (Bajtín, 2003, p. 70).

\section{¿Un soñador, un hombre de subsuelo?}

La reflexión sobre la "homosexualidad", como afirma Eribon, está muchas veces marcada por representaciones homófobas, dentro de la estructura heterocentrista que sólo puede concebir la sexualidad en la diferencia y complementariedad de lo masculino y femenino. Esta estructura fue legitimada por el psicoanálisis, que terminó por entender la "homosexualidad" como "[...] una sexualidad o una afectividad que carece de algo: es una «perversión», algo «detenido» en un estadio infantil en el 
desarrollo normal del individuo y de sus deseos, una «incapacidad» de reconocer al «otro», etc." (Eribon, 2001, p. 126).

Este ligamen de la "homosexualidad" con la enfermedad mental está ahí presente desde el siglo XIX hasta hoy. En este sentido, el insulto "loca" convoca no sólo una diferencia a partir de la "exposición desvergonzada" de rasgos femeninos en un hombre, sino, también, una situación en el mundo: el "homosexual" no es un hombre completo (dentro de este sistema de clasificaciones) y, por tanto, debe ser relegado al ámbito del "error" (que para el paradigma, no es sino el ámbito de lo femenino ${ }^{11}$ ). Afirma Eribon:

No sólo las categorías interiorizadas se exponen siempre en forma de rasgos ridículos o descalificadores, sino que el discurso dominante y «legítimo» siempre asocia a las personas con características generales y proximidades «desacreditadoras» como el delito, la inmoralidad, la enfermedad mental, etc. El individuo «inferiorizado» ve cómo le es denegado así el estatuto de persona autónoma por la representación dominante, puesto que siempre se le percibe o se le designa como una muestra de una especie (y de una especie condenable, siempre más o menos ridícula) (Eribon, 2001, p. 105).

Parece, según la deconstrucción que Eribon hace del pensamiento de Foucault, que en la sociedad, desde la época moderna («a partir del 
clasicismo»), la moral burguesa va a imponerse desde la familia (ámbito privado) hasta el trabajo (ámbito público), instaurando una división entre la razón ${ }^{12}$ y la sinrazón; la segunda tiene que ver con aquello que violente las reglas sociales "racionales"; por supuesto, en este espacio entra la locura, a la que se aúnan todos los proscritos ${ }^{13}$, es decir, todos aquellos que ya no pueden ni deben formar parte de la sociedad: "Y la sociedad se erige en adelante por la «gran idea burguesa, y en breve republicana, de que la virtud es también un asunto de Estado» y que «puede imponer decretos para hacerla reinar»" (Eribon, 2001, p. 374-375).

El estereotipo de la "loca", entonces, participa de este orden, que, además, viene a cerrar la "identidad" del otro "homosexual" (de ahí que se pueda definir el estereotipo como un fetiche, en el sentido freudiano del término). La "loca" no puede ser más que lo que el heterosexual define con su injuria: la "loca" es coartada en su libertad de reinvención ${ }^{14}$. Es fundamental, pues, cancelar esta injuria, apropiársela con el fin de quitarle toda su violencia y resignificarla.

Así las cosas, se va a resemantizar el término "loca", que, a la luz de la teoría expuesta y para el caso de Germán Germanóvich, el héroe de la novela de Quesada, solo puede entenderse positivamente. La «loca», en esta novela, es un hombre fuera de lo común, un hombre no como todos, para utilizar la expresión bajtiniana. Con este trabajo, entonces, se quiere revalorizar este 
término, quitándole su carga injuriosa, para resaltar su carácter productivo ${ }^{15}$. Así, el personaje "loco/loca" de esta novela, solo lo sería, realmente, desde el discurso monológico, pero no desde la perspectiva de la literatura carnavalizada ${ }^{16}$.

La "loca", en el texto de Quesada, es "loca" en tanto rehúye la norma general, en tanto abandona la "vida habitual", para entrar en lo que, se podría llamar, una "vida excepcional", la cual, en la narración de este personaje, está definida por la literatura, por la ficción. Germán Germanóvich, de hecho, utiliza -desde el inicio de la novela-el discurso homófobo a su favor. Así, en lugar de reafirmar la virilidad normativa, se apodera de la feminidad por la que se le acusa, la hace suya y, con ella, lucha contra la violencia del estereotipo:

"Me digo: "aparece la Bella Durmiente reinstalada en su trono. Todas las brujas están muertas, las hadas madrinas posan discretas a un lado, el pueblo me adora a prudente distancia. Mi príncipe de labios carnosos y encarnados de puro deseo, aguarda para llevarme muy lejos o quizás un poco más allá, de nuevo al bosque, para desahogarnos rapidito de tantísima urgencia y amor pospuesto". Me digo: "la Niña cae dentro del árbol mágico con un vértigo que primero le hace cosquillas en el bajo vientre y después se transforma en un lento, suave flotar. La falda se abre atenuando la caída, una brisa húmeda se mete entre mis piernas y 
me doy cuenta que los abismos son también placenteros" (Quesada, 2005, p. 14) (Resaltado mío).

El «humor de loca» ${ }^{17}$ se explica, acá, como una de las múltiples estrategias de resistencia o de reapropiación de la acusación de afeminamiento, así -y más importante para este trabajo- como una de las expresiones de la gran creatividad e inventiva de Germán y, en él, de una «cultura minoritaria», para utilizar la expresión de Eribon. Realmente, la «excentricidad» de Germán es parte fundamental de su humanidad; es decir, su humanidad no se puede concebir sin los elementos de cierta "locura". Sin embargo, como ya se ha dicho, esta locura no es para nada negativa, es más bien deseable en este tipo de personajes ambivalentes, personajes que, sin embargo, son conscientes de su excentricidad. La plenitud de autoconciencia (como apunta Bajtín para el caso de Sueño de un hombre ridículo, de Dostoievski) es representativa, entonces, en Germán Germanóvich, como, en general, en este tipo de personajes que saben mejor que nadie sobre su "locura"; al respecto, la siguiente cita:

Pensándolo bien, en todo reencuentro que se precie hay un abrazo de por medio, quizás me falta ese ingrediente mágico. Entonces pongo mi maleta junto a la base del falolápiz y me dedico a pedir abrazos. Algunos transeúntes apuran el paso y me ignoran con un gesto [...]. En definitiva pasan las personas, me escuchan y huyen. [...] No falta quién 
ría, se asuste o haga un comentario insultante, pues es cosa de locos y vagabundos eso de pedir abrazos (Quesada, 2005, p. 17) (Resaltado mío).

Germán, entonces, pertenece a este tipo de personajes que Bajtín caracteriza como estrambóticos, pero que, al mismo tiempo, tienen una aguda conciencia de sí mismos y de todo; no poseen, además, ni un poco de ingenuidad. Evidentemente, este hombre que sabe la verdad, que la busca y del cual se ríen todos, es una parte importante de la estructura de esta novela. Según Bajtín, la posición que adquiere este tipo de personajes es característica del sabio en la menipea, el sabio como portador de la verdad, pero una verdad que los demás consideran locura o estupidez.

Así las cosas, es evidente que esta "locura especial" es un rasgo que define al héroe de la novela de Quesada. Respecto al papel e importancia del héroe ${ }^{18}$ en la novela polifónica, Bajtín señala que, a Dostoievski:

[...] el héroe le interesa en tanto que es un punto de vista particular sobre el mundo y sobre sí mismo, como una posición plena de sentido que valore la actitud del hombre hacia sí mismo y hacia la realidad circundante. A Dostoievski no le importa qué es lo que el héroe representa para el mundo, sino, ante todo, qué es lo que representa el 
mundo para él y qué es lo que viene a ser para sí mismo (Bajtín, 2003, p. 73) (Resaltado del autor).

La importancia del héroe, desde la teoría Bajtiniana, está en su reflexión: el héroe al que se refiere Bajtín es un héroe que habla sobre sí mismo y sobre su mundo. De este aspecto surgen los métodos de representación y caracterización específicos de la novela polifónica. Lo anterior es lo que, precisamente, hay que analizar en el protagonista de esta novela, Germán Đ El Gado. Siguiendo a Bajtín, habría que apuntar, desde ya, que no se está, en El gato de sí mismo, ante determinado «modo de ser», ni la imagen del protagonista es rígida: Germán Đ El Gado se caracteriza, más bien, por una representación desde la inestabilidad. Lo que se sabe sobre Germán Đ El Gado es, para seguir la expresión de Bajtín, el "último recuento de su conciencia y autoconciencia" y, al final del texto, su "última palabra acerca de su persona y de su mundo" (Bajtín, 2003, p. 49).

Bajtín, en un pie de página, explica cómo Dostoievski nunca concretó su idea de una novela autobiográfica, en la que iba a representar la "historia de una conciencia en proceso de desarrollo". El gato de sí mismo, de alguna manera, realiza este trabajo de representación: esta novela se presenta como una autobiografía y su personaje principal, su héroe, como una conciencia de la que no se sabe más que lo que ella misma dice sobre su mundo y sobre sí. A 
Germán Đ El Gado (como afirma Bajtín para el caso de los héroes en Dostoievski) no es posible verlo, pero sí oírlo. Explica Bajtín:

Por consiguiente, los elementos que componen su imagen [se refiere a la imagen del héroe] no son rasgos de la realidad, tanto de sí mismo como de su entorno cotidiano, sino el significado de estos rasgos para él, para su autoconciencia. Todas las cualidades estables y objetivas del héroe, su tipicidad sociológica y caracteriológica, su habitus, su mundo interior y hasta su misma apariencia, es decir, todo aquello que suele servirle al autor para la creación de una imagen estable y definida del héroe (el "quién es"), todo ello viene a ser para Dostoievski el objeto de la reflexión del mismo héroe, el objeto de su autoconciencia, y la misma función de esta autoconciencia es el objeto de la visión y representación del autor (Bajtín, 2003, p.74) (Resaltado del autor).

El autor "real" de El gato de sí mismo se vuelve irrelevante para el lector, ni siquiera su manifestación lingüística (como autor textual o como una especie de narrador) forma parte de esta novela. Acá, el único horizonte que define el 
relato es el horizonte del héroe, quien habla con libertad. El héroe es el único sujeto relevante para la comunicación literaria que establece esta novela. $E l$ gato de sí mismo le pertenece a Germán Đ El Gado y Germán Đ El Gado es El gato de sí mismo. El héroe de esta novela es, además, un héroe que sabe contar, es un narrador de su autoconciencia y, en este sentido, hay que entender su trabajo como una labor artística, ya que toda actividad narrativa es, finalmente, una actividad que produce ficción, y es, precisamente, gracias al trabajo ficcional que «la loca» Germán Đ El Gado puede travestirse y travestir ${ }^{19}$ su mundo, en un afán por instituir una "verdadera heteronimia de las cosas" (para usar una frase de Barthes): Germán Đ El Gado juega con el signo como con una ficción.

El proceso de autoconciencia de Germán Đ El Gado integra no solo a su propia realidad sino, además, a su mundo exterior y a la vida cotidiana. Germán Đ El Gado, en este sentido, es un héroe consciente de toda su existencia y su labor no es solo concienciarse a sí mismo, sino, además, concienciar al mundo. Lo anterior es claro en el texto de Quesada, donde el mismo narrador define (aunque burlonamente) su autobiografía como un "libro inspiracional" y su investigación, como un mandato divino: Dios es quien le pide volver a Cartago a resolver el misterio en torno a su padre. 
La autoconciencia de Germán Đ El Gado activa, pues, su labor creadora sobre sí mismo y sobre la realidad que lo rodea. Cambiar el mundo a punta de palabras no hace sino revelar una negación contra cualquier rasgo estable, homogéneo, limpio, en un afán por liberarse de todo querer-asir. Entonces, esta labor creativa y concienzuda del narrador-protagonista de la novela de Quesada tiene como fin la liberación de lo que se podría llamar la tiranía de la realidad establecida. En efecto, Germán Đ El Gado se dice y dice al mundo desde la fantasía, desde la ficción:

No quiero pensar en mis seres queridos, pero tampoco puedo evitarlo.

Dios me reprende a menudo, en verdad me halaga y regaña al mismo tiempo cuando dice: "Pensás demasiado. Nada parece existir si no está en tu cabeza". Tiene razón, cada paso mío no es sino una vibración dentro del universo incomprensible e ilimitado de mi fantasía (Quesada, 2005, p. 342).

Es posible, a partir de la teoría expuesta, caracterizar al héroe de esta novela como un "soñador" y, al mismo tiempo, como un "hombre del subsuelo" (según las categorías propuestas por Bajtín para el caso de la novela de Dostoievski). El "soñador" es definido por Bajtín como un héroe que quiere y no puede materializar su ilusión. Sobre este aspecto, la figura de Germán Đ El Gado es clara: Germán Đ El Gado es un hombre enamorado. Íñigo es su objeto de deseo; sin embargo, conforme pasan las páginas, este personaje se 
establece más del lado de la ilusión que del de la realidad. De hecho, Íñigo podría entenderse como el espacio de la utopía, como la patria amada, como el corpus deseado, pero nunca alcanzado:

Digamos que te llamás Íñigo. Me gusta tu nombre, ¿sabés?, no suena a nada ni a nadie conocido, no tiene lazos al padre ni al abuelo ni a ningún otro antepasado, suena fresco, como acabado de inventar en ese libro de aventuras donde Íñigo es un adolescente que se hace hombre junto a un caballero triste, un tipo fiero y bigotón [...] (Quesada, 2005, p. 283).

Pienso, Íñigo, que quizás pueda tener contacto con vos, aunque sea a través de una persona dotada de acceso a los mundos superiores. ¿Te voy a encontrar, querido? ¿Habrá valido la pena viajar desde tan lejos? He hallado a mi padre mudo, a mi hermano ausente, a mi nana vieja, a mis amigos lejanos, a mi madre tan muerta que ya ni se le nombra... ¿Vos dónde te has metido? (Quesada, 2005, p. 292).

Bajtín explica cómo el "hombre del subsuelo" destruye todos los rasgos firmes de su aspecto. Sobre el "hombre del subsuelo" no hay definiciones seguras, no hay nada -afirma este teórico-qué decir de él: "El "hombre del subsuelo" no sólo disuelve en sí todos los posibles rasgos firmes de su aspecto haciéndolos objeto de su reflexión, sino que simplemente ya no tiene 
estos rasgos, [...] aparece no como un hombre de la vida real sino como un sujeto de la conciencia y del sueño" (Bajtín, 2003, p. 78).

Como es claro, este tipo de héroes nunca coincide consigo mismo. Si algo lo caracteriza es, más bien, su falta, la cual no puede ser nunca resuelta, según afirma Bajtín para el caso de los héroes de Dostoievski. La idea de la falta de conclusión es fundamental para la comprensión de Germán Đ El Gado y, en este sentido, sería importante reafirmar la organicidad del juego narrativo presente en esta novela.

El «travestismo literario», las muchas vestiduras que (re)velan a Germán Đ El Gado y a su mundo, no hace sino patentizar la falta de conclusión de este héroe y su constante trabajo de (de)construcción sobre sí mismo y sobre el mundo que lo rodea:

Justo antes de detener por completo el autobús, el chofer aprieta un botón y siento a mis espaldas el resoplido de un dragón enfermo: "acaban de abrir la escotilla de tercera clase del Caribbean Princess", me digo.

[...] Me digo: «Ladies and gentleman, la Cenicienta está apunto de descender con sus zapaticos de cristal por la amplia escalinata de 
palacio». [...] Me digo: «aparece la Bella Durmiente reinstalada en su trono. Todas las brujas están muertas, las hadas madrinas posan discretas a un lado, el pueblo me adora a prudente distancia» (Quesada, 2005, p. 13-14).

El héroe de El gato de sí mismo rompe constantemente los límites entre la realidad convencional y la fantasía, pero como un trabajo artístico que atenta contra la estabilidad -para él odiosa- de los discursos que busquen (de)limitarlo y (de)limitar su mundo. La realidad convencional siempre está ahí para hacer miserable a Germán Đ El Gado y, por ello, le son fundamentales los muchos discursos que escoge para (re)inventarla y (re)inventarse, en un movimiento que pone en crisis su ciudad natal (que aquí hay que entender como "ciudad impuesta"), su sexualidad normativizada y su “identidad” preestablecida. Germán Đ El Gado se da a la tarea de escoger (muchas veces desde la pura invención): escoger nuevos espacios, nuevas identidades, nuevos vínculos amorosos, etc., que lo conformen como un "hombre no como todos", un hombre que, incluso, escoge su muerte:

Detrás de mí van desapareciendo los palacios, las torres puntiagudas, los magníficos mercados de la vieja Cartago. La gente a mi alrededor lee sus revistas, conversa por teléfono celular, me borra inmediatamente de su mente. Pienso entonces, Íñigo, si vos me estarás extrañando. Quizás lo haga la malvada Rasputina cuando se entere de que me fui. 
De seguro Yaneri Solitari cabalgará de un lado a otro la sabana gritando mi nombre. Tal vez Odalisca se pregunte desconsolada quién comprará sus alfombras y se hará cargo de su torpe sombra. Abtuló, el libanés, estrujará en sus manos el -ahora inútil- papelito con el número telefónico de palacio. Muy pronto todos se enterarán de que he desaparecido (Quesada, 2005, p. 341).

Otro aspecto que explica Bajtín sobre el "hombre del subsuelo" es que éste piensa más que nada en lo que piensan y pueden pensar de él los demás. En todos los puntos críticos de sus confesiones busca, por ello, prever una posible definición y valoración de su persona por los otros (Bajtín, 2003, p. 81). Al respecto, es importante citar el siguiente extracto de El gato de sí mismo:

Esa tarde, Su Majestad comió muy poco, apenas unas cucharadas de arroz y frijoles, medio aguacate, un vaso de tamarindo y postre. Ningún platillo le produjo bienestar, ni siquiera el dulce de coco que tantas veces le había traído sueños del mítico edén. Su ceño no paró de señalarme, lo sentía sobre mí a pesar de la distancia enorme que nos separaba. Sus ojos me transmitían un odio inédito, su piel mostraba el tono cenizo de los coléricos y los dolientes. Yo no sabía pero sí sabía, Ínigo: la furia real rondaba mis posesiones desde tiempo atrás, acechándome igual que un felino, lista para abalanzarse sobre mis 
entrañas. Mis otacustas habían dado informe de la inminente expulsión, pero ignoraban el momento, ese punto donde mi vida sería dolorosamente libre (Quesada, 2005, p. 58).

Esta profunda conciencia de lo que piensan los otros es fundamental para entender a Germán Đ El Gado como un "hombre del subsuelo". Toda su autobiografía, de alguna manera, se sostiene en la especial preocupación del protagonista por dar testimonio y, al mismo tiempo, por justificarse y por entender su propia existencia, al lado de la de los otros. Igualmente, habría que apuntar que, cuando Germán Đ El Gado piensa sobre lo que piensan los demás sobre él, se evidencia su situación en el mundo: el protagonista sabe del rechazo y, por ello, trata de adelantarse, trata de anticipar los discursos ajenos sobre él mismo, sobre su "condición":

Mientras comíamos, el silencio hacía el recuento de los cargos contra mí: Os han visto con los fondillos al aire bajo el entarimado de la plaza de toros y entre las rocas sueltas de las ruinas de la gran parroquia. Os han sorprendido mirando a otros jovencitos con lascivia y provocación. Os han escuchado bufar de placer en varios hogares respetables. Os han delatado vuestros mismos compañeros de actos contra natura, quienes accedieron a firmar confesión al pie del potro, la horca y la hoguera. Os acusamos de atentar contra la voluntad de Dios, de la naturaleza y del 
Rey, y tal crimen se paga con la muerte o el destierro. ¿Tenéis algo que decir a vuestro favor, Hermann Wilde? (Quesada, 2005, p. 59).

Y con lo anterior, es importante recalcar que el "hombre del subsuelo" no es nunca concluido por este conocimiento sobre la conciencia ajena. El "hombre del subsuelo" maneja esta información de los otros sobre él y, por ello, puede utilizarla, jugar con ella, volverla, finalmente, «inadecuada», según una expresión de Bajtín. La última palabra le pertenece -siempre- al "hombre del subsuelo", y Germán Đ El Gado patentiza esto cuando refiere, hacia el final de la novela, cómo Dios mismo confeccionará su lápida, donde se podrá leer su última voluntad:

Dios, tan preciso para la confección de piedras funerarias, me ha prometido que mi humilde tumba será visitada por gente de todo el mundo. Tendrá un sol entre nubes, un recipiente para poner margaritas y una lápida en la que las futuras generaciones podrán leer mi última voluntad, el fin de mi autobiografía y mi última confesión al mundo:

Aquí seguirá descansando Germán Germanóvich (Quesada, 2005, p. 343).

Con lo dicho, es claro que toda la estructura artística de esta novela se dirige hacia la representación y la comprensión del discurso del héroe. Germán Đ El 
Gado, en efecto, domina el texto, su palabra se oye a lo largo de esta novela y, para poder realmente acceder a ella, se debe incursionar en la fantasía que atraviesa toda la verdad de este personaje. La fantasía que desarrolla Germán Đ El Gado en su narración hay que entenderla como un juego, un juego que traviste la realidad, con el fin de evidenciar el carácter artificioso de esta. La fantasía, finalmente, viene a instaurar la duda como la mejor manera de poner en entredicho cualquier rasgo estable sobre el héroe mismo o sobre su mundo.

Respecto a la verdad del héroe, es importante explicar que esta solo puede ser "la verdad de la conciencia propia" (Bajtín, 2003, p. 86), y solo puede surgir de los labios de, en el caso de El gato de sí mismo, Germán Đ El Gado. De lo anterior, se deduce la relevancia de esta narración en primera persona; incluso su forma de enunciado confesional (propio del género autobiográfico ${ }^{20}$ ) ratifica esta ligazón entre la verdad del héroe y su palabra. Las características del género autobiográfico, en efecto, permiten -de una manera más orgánicaactivar la palabra del héroe. Según lo que apunta José María Pozuelo Yvancos, la autobiografía surge con el cristianismo, sobre todo a partir del fenómeno de la confesión. Afirma este estudioso:

En esta retórica [se refiere a la retórica de la confesión] se incluye el fenómeno de la apelación al otro para presentarle la verdad sobre lo que uno es, por encima de la imagen exterior o primera. Y en esa presentación hay un carácter reivindicativo de la verdad sobre uno 
mismo, de la propia imagen. La autobiografía dialoga siempre con un tú en la medida en que el autobiógrafo quiere que se haga justicia. En toda biografía hay un principio de autojustificación ante los demás (Pozuelo Yvancos, 2006, p. 60).

Bajtín, de hecho, señala que, para Dostoievski, “[...] sólo en forma de un enunciado confesional puede el hombre emitir [...] la palabra última que le sea realmente adecuada" (Bajtín, 2003, p. 86). Con lo dicho, es claro cómo esta novela juega con la retórica de la veracidad, la cual, como explica Pozuelo Yvancos, se sitúa en la base de toda confesión, confesión que, para el caso de El gato de sí mismo, se dirige a Dios, a Íñigo y a los "hombres", pero, sobre ellos, a sí mismo. Dios, de hecho, es un personaje más dentro de la narración de Germán Đ El Gado. Dios (como sucede en la autobiografía de San Agustín) es, acá, un testigo y un interlocutor del héroe, un héroe que, entonces, ofrece su verdad, pero de una manera singular, según se ha podido colegir con todo lo dicho hasta ahora.

Es un hecho que el relato de Germán Đ El Gado no se queda en una simple forma de introducir su confesión: El gato de sí mismo, con su «travestización literaria» (activada por la "fantasía" misma del héroe), permite oír la palabra del protagonista sin destruir la autenticidad de su narración y sin romper su tejido, sin menguar el collage que ofrece al tú de su narración: Dios, Íñigo, las generaciones futuras. La (auto)biografía no es solo la historia de vida de una 
persona, más importante aún para este análisis, es concebirla como un género literario, como una construcción artística, que, entonces, implica una concepción estética, procedimientos de realización y un manejo consciente y explícito: Germán se escribe y le escribe al mundo $s u$ verdad.

El discurso autobiográfico de Germán Đ El Gado, en efecto, es toda una creación; es decir, toda una "obra de ingenio", que revela su gran inventiva: la narración de este héroe no es sino el planteamiento de su poiesis, de su virtualidad creativa, y esta creatividad es la que le permite atentar contra los conocimientos (los discursos) que han buscado y buscan constantemente concluirlo. La ficcionalización-travestización literaria que desarrolla este personaje lucha contra el trabajo de estabilización de los discursos de poder, y ello explica que el héroe-ideólogo, la «loca» de esta novela, defienda, sobre todas, su idea de inventarse. Idea que, precisamente, implica que el ser humano no es una dimensión finita y determinada, como explica Bajtín.

'Inventar' no solo aclara la posibilidad del descubrimiento sobre sí mismo y sobre el mundo, sino que, además, introduce, como se ha visto, el trabajo creativo (literario, en este caso) como parte fundamental de la libertad del ser humano, el cual, por tanto, puede "[...] romper con el marco conclusivo y mortífero en que lo encierran las palabras ajenas.” (Bajtín, 2003, p. 91) Al respecto de lo anterior, léase la siguiente cita sobre una pérdida colectiva de memoria. Esta se da en un autobús en el que viajaba Germán Đ El Gado en 
ruta hacia su nueva vida, alejada de Cartago. Sobre todo, hay que poner atención en el final del texto:

El hombre sentado junto a mí siguió quejándose hasta darse cuenta de que repetía incoherencias, porque no recordaba el motivo de su disgusto. Unos pasajeros trataron de averiguar qué hacían en ese autobús, para dónde iban, cuál día de la semana era aquél. Minutos después nadie recordaba ninguna canción, ningún pasajero había visto subir a un ciego y a su lazarillo al autobús, ni tenía certeza siquiera de su propia identidad. El vehículo chocó contra un arbusto cuando el chofer olvidó cómo conducir. A punto de perder la memoria por completo, logró abrir la portezuela y echarse a correr. Yo bajé antes de olvidar mis motivos para marchar. Me alejé del bus lo más rápido que pude, mientras los pasajeros se arrastraban por el suelo, balbuceaban sonidos y volvían a empezar de cero, con la memoria y el dolor limpios, dispuestos a inventarse un nuevo pasado y una nueva historia (Quesada, 2005, p. 86-87) (Resaltado mío).

Como explica Bajtín, nunca se puede aplicar al ser humano la fórmula de “identidad $A$ es igual a identidad $A$ ”. El gato de sí mismo, en este sentido (y gracias al «travestismo literario» que se le ha señalado), muestra la "vida 
auténtica de una personalidad". La autenticidad hay que entenderla, precisamente, como el punto vital en el cual el ser humano se sale de los límites de lo predefinido. Evidentemente, para ser este un movimiento orgánico, debe ser a voluntad, debe ser consciente, como lo patentiza Germán Đ El Gado. La autenticidad está, pues, en huir de lo esperado hacia lo inesperado, en una búsqueda constante por la libertad. Véase la siguiente cita de la novela de Quesada:

Usé mi astucia y muchos disfraces para que los espías del Rey nunca me encontraran. Fui mendigo, mago, malabarista, genio del trapecio, tahúr, personaje de Julio Verne, la muerte mexicana un dos de noviembre. Fui yo, vos, la otra persona. Aprendí de los esclavos negros a convertirme en piedra, agua, árbol. Me transformé en veneno y, con excepción de las serpientes, todos se alejaron aterrorizados. [...] Con el propósito de dormir en casas de desconocidos trasmuté en flor plástica, en la marialuisa de la foto matrimonial, en el tapete bordado por la abuela y la tacita fina que sólo se usa cuando llegan visitas elegantes (Quesada, 2005, p. 90).

Se entiende, pues, con esta actitud del héroe de El gato de sí mismo, un "rechazo de la penetración ajena en las profundidades de la personalidad" (Bajtín, 2003, p. 93). Se rechaza cualquier intromisión que busque concluir al ser humano, que busque encasillarlo, quitarle la profundidad a su "alma", la 
cual, entonces, solo puede ser revelada, como sucede en esta novela, por el héroe mismo, y de ello se deduce la importancia de sus "memorias".

Cualquier discurso (psicológico, psicoanalítico, psiquiátrico, científico o judicial) que busque cosificar el "alma humana" debe provocar una

\section{A manera de conclusión} profunda sospecha, en la medida en que se atenta contra esa especial indefinición que Dostoievski buscaba representar en sus propios héroes, indefinición que Germán Đ El Gado busca resaltar en sí mismo y proteger de los "agentes" que le vienen a quitar la "felicidad". La indefinición, con lo afirmado, no es otra cosa más que humanidad, la inconclusión (in)determina al héroe:

«Se parece usted a don Alberto en lo barrigoncito, pero ese pelo largo y esa barba al estilo Buffalo Bill no son muy corrientes por estos lados...»

Empiezo a incomodarme. Yo creía que estaba reproduciendo la moda masculina de Víctor Manuel II, Rey de Cerdeña. Estaba seguro de recordar al Errol Flynn en sus papeles de aventurero. ¿Qué está pasando con mi cuerpo? ¿Acaso me traiciona? ¿O por el contrario, se transforma para protegerme de un mal que mi natural abierto e ingenuo me impide percibir? ¿Será casual la mención del detective? (Quesada, 2005, p. 171). 
Solo resta reafirmar que la representación de la autoconciencia de Germán Đ El Gado es, pues, dominante en la estructuración de la imagen de este héroe, imagen que requiere, como se ha visto, una atmósfera artística especial, en la que, como explica Bajtín, todo se refiera al héroe: “[...] todo debe tocar en lo vivo al héroe, lo debe provocar, interrogar, incluso polemizar con él y burlarse de él, todo debe estar dirigido al héroe mismo, todo debe percibirse como la palabra acerca del que está presente y no como la palabra sobre el ausente [...]" (Bajtín, 2003, p. 99) (Resaltado del autor).

Germán Đ El Gado narra y, al hacerlo, moviliza los discursos que conforman esta novela, la cual representa, entonces, las crisis y las rupturas de este héroe: el narrador cuenta su vida en el umbral, en un momento de crisis y de cambio. De ello se deduce que, en El gato de sí mismo, todo lo que forma su contenido se deriva de la conciencia del protagonista. Todo lo que él ve, conoce, revela, etc., se atrae hacia la palabra bivocal y activa el diálogo permanente que lo caracteriza a la hora de contarse.

Germán Germanóvich es un personaje que asume su calidad de exiliado, de "paria", de "anormal", tanto que él mismo afirma que nadie podría entender su mundo, un mundo fruto del rechazo y la negación: "No sé cómo decirle a don Luis Dieciséis que la princesita renuncia de nuevo a sus privilegios. No sé si vale la pena recordarle que mi mundo es otro, que muy pocos lo conocen" (Quesada, 2005, p. 326). 
Como señala Eribon, en la medida en que «uno» se sitúa en el espacio social, cultural y sexual de la normalidad, puede entonces señalar las "deformidades" de los «otros». Estos «otros», por el contrario, no tienen más opción que estar fuera de los parámetros de «lo normal», y lo único que pueden hacer es reivindicar la "anormalidad" en la que han sido inscritos. Germán, en este sentido, escribe, con su narración autobiográfica, un elogio de la locura, de su locura especial.

La locura sin sentido que otros encuentran en Germán Germanóvich es, para él, su principio de vida: eso que "debería" avergonzarlo, por el contrario, es el centro de su creatividad. Su trabajo creativo, además, tiene un fin personal y colectivo, como se señaló desde la introducción. Germán, de hecho, es un "héroe político", por lo que no extraña que constantemente califique su obra como un documento de gran ayuda para las futuras generaciones, una guía para el buen vivir, un libro para evitar los conflictos entre las naciones, etc. Lo anterior se puede entender a partir de lo apuntado por Eribon sobre los gays: la historia de vida de un gay pone en relación a todos los gays; así, cada gesto individual por la liberación no es sino un movimiento colectivo.

Como se ha señalado con Bajtín, el héroe de una novela polifónica se distingue por su discurso, un discurso del cual es dueño y señor, y que no admite análisis (psicológico) alguno. No es posible, entonces, comprender orgánicamente la labor de Germán si no se trata desde el punto de vista de 
una «moral de lo minoritario» ${ }^{21}$; es decir, de la moral como estética, “[...] como creación de sí mismo y reorganización siempre por recomenzar de «pedazos» que sería vano pretender reunir un día en una totalidad cerrada y concluida..." (Eribon, 2004, p. 321).

El héroe de El gato de sí mismo, desde la estigmatización que ha sufrido y por ella, sabe escaparse del mundo que lo condena, y se inventa, sueña, fantasea, para transformar su situación "vergonzosa" en orgullo, de ahí que, hacia el final del texto, pueda romper definitivamente con su padre -la figura que más lo ha acosado a lo largo de su historia ${ }^{22}$-, para salir en busca de nuevos rumbos, nuevas misiones. Explica Eribon, para el caso de la obra de Jean Genet: "El individuo es desposeído de su personalidad por ser un mero representante de una especie monstruosa. Pero el sujeto asume esta metamorfosis y la asume, se apropia de lo que se ha hecho de él y transforma, de manera imprevisible e incontrolable, las significaciones y los efectos sociales y culturales" (Eribon, 2004, p. 96).

El trabajo literario de Germán es -como se ha visto- un medio para reinventar su vida, un medio para transformar el significado predeterminado. Esto es lo que Foucault llamó la "estética de sí mismo", que no hay que desligar tampoco de lo apuntado sobre «la loca» y «la travestización», nociones que participan de este «trabajo de huida» que lo que finalmente busca es escapar a 
la colonización del "espíritu”: es, como se afirmó con Bajtín, «un rechazo de la penetración ajena en las profundidades de la personalidad».

Es importante apuntar que Germán parece estar, hacia el final de la novela, decepcionado por todo. Este héroe lo evidencia con una actitud muy propia de la menipea cínica o estoica: el desinterés, el tedio. Esta actitud del héroe de $E l$ gato de sí mismo se puede explicar por la certidumbre de que fuera de sí mismo, fuera de su "fantasía", todo está en su contra, o, quizás, porque añora a su amado, cuyo alcance parece imposible. También se puede explicar (tal vez de una manera más precisa) como el fruto del repetido rechazo de su padre, a quien él despierta de un profundo sueño justo al finalizar la segunda parte del texto. La reacción de su padre no hace sino aclararle que él es hijo del rechazo (otra forma de la injuria ${ }^{23}$ ). «Somos los hijos de la injuria», afirma Eribon, quien continúa:

El efecto de los insultos precede a su enunciación, puesto que no son más que la expresión de las estructuras sociales, raciales [24], sexuadas, sexuales, de dominación, y que estas mismas estructuras, incorporadas a lo largo de la infancia y de la adolescencia, son las que han fabricado nuestra subjetividad. La injuria hace vibrar resortes ya instalados en el inconsciente individual y en el cuerpo por el proceso de la socialización y el aprendizaje (Eribon, 2001, p. 86) (Resaltado mío). 
Así, hay que agregar a la descripción de este héroe el tedio ante el mundo, un tedio fruto de la evidencia de su condición de "paria". Germán, por tanto, no tiene más salida que la transfiguración ${ }^{25}$. Este término debe, además, entenderse (siempre en relación con el final de la novela) en su sentido religioso: Germán se entrega a su último cambio (nuevamente en un acto consciente) que lo mostrará en su estado glorioso, es decir, heroico, hasta el final de los tiempos... La muerte de Germán no sería más que su último impulso hacia el amor (ya que, al final, su nueva misión es ir en busca de Íñigo), según lo explica George Bataille en su libro El erotismo.

Y con lo anterior, ¿es posible explicar de manera contundente el tono "derrotista" de Germán hacia el final del texto? A la luz de lo analizado sobre la novela polifónica, la actitud del héroe de esta novela concuerda con lo explicado por Bajtín: Germán se encuentra en el «umbral», y de ello se deduce la representación moral del protagonista en el "Epílogo y rebobinado". Esta parte, en efecto, presenta la narración de los últimos instantes de la conciencia del narrador, una conciencia que, en realidad, siempre se ha encontrado en el límite. En este sentido, un hombre del subsuelo como Germán, quien ya no conserva ningún vínculo, acepta la muerte como su último movimiento hacia la libertad (¿no es, acaso, el suicidio de este personaje su última elección consciente sobre sí mismo?, como se dijo antes). Así, la escena final de esta novela termina de desnudar el "alma" de Germán: se rompen de alguna manera, como afirma Bajtín, «los 
hilos pesados» de la mentira oficial (la mentira del padre traidor) y de la personal (Germán, a pesar de su esfuerzo, no deja de ser un "paria").

Esta actitud del héroe de El gato de sí mismo con respecto a su muerte aproxima, como es claro, al misterio. Sin embargo, el misterio no es más que una renovación -en este punto de su historia de vida- de los esfuerzos del narrador-protagonista: ¿no se puede, pues, entender la muerte como un "viaje fantástico", cargado, además, de elementos utópicos (Germán va en busca de Ínigo)? La muerte, en estos términos, constituye un nuevo plano de acción, que, además, destruye lo que Bajtín llama "la simple totalidad de la imagen del héroe" (Bajtín, 2003, p. 216).

Desde otra perspectiva, se podría esperar de la novela de Quesada una gota de esperanza, de fortaleza en la lucha de los sujetos subalternos (ya que se ha entendido este texto costarricense como un trabajo profundamente político); sin embargo, es claro el objetivo de Quesada en torno a su novela: con $E l$ gato de sí mismo, se busca desenmascarar completamente lo siniestro de los poderes. En este sentido, el tono pesimista del personaje tiene un objetivo definido: denunciar lo ominoso de la situación de los sujetos subalternos, quienes -incluso- se ven obligados a inmolarse, como es el caso de Germán Germanóvich, un personaje que, al término de su viaje, ya no tiene fuerzas para seguir su enfrentamiento, su lucha contra un sistema que lo oprime desde todos los frentes posibles. No extraña, con lo dicho, que el "Epílogo y 
rebobinado" de la novela de Quesada termine haciendo referencia a Antonin Artaud, padre del teatro de la crueldad:

«Yo sé adónde iba Antonin Artaud esa mañana de 1948, cuando alrededor de las siete lo encontraron muerto en su catre, con una bota puesta y la otra en la mano.»

Miro hacia un extremo del cuarto y veo al buen Józek T. Korzeniowski con un libro entre las manos, despreocupado aunque ya debemos irnos, y él aún no está preparado. Lee en voz alta sobre la enfermedad del señor Artaud y repite una y otra vez la pregunta del autor del libro, quien se imagina esa mañana en el sanatorio de Ivry-Sur-Seine, donde la muerte soprendió a Artaud preparando un viaje. Yo sé su destino, Jozék, Dios me lo ha dicho: Se fue a buscar a sí mismo donde nadie nunca lo viera [...] (Quesada 2005, p. 331).

Eribon señala cómo el sujeto es, finalmente, un sujeto histórico ${ }^{26}$. Eribon, claramente, se centra en la cuestión gay para resaltar ese vínculo del sujeto gay con todos los gays de la historia. No extraña, en este sentido, que Germán ligue, pues, su "condena" con la condena del escritor Oscar Wilde, ni su "final" con la muerte del escritor Antonin Artaud, quien -como se sabe- desarrolló un profundo odio, a lo largo de su vida y evidenciado en su obra, por la psiquiatría, una de las instituciones que más se han abocado a perpetuar el «orden sexual» establecido. 
1. Como lo hace Didier Eribon, se emplea la palabra «gay» por el simple motivo de que es la palabra con la que actualmente se designa a las personas "homosexuales". Afirma el autor francés: "Elegir la palabra «gay» es reconocer la legitimidad y la necesidad del movimiento de afirmación de uno mismo que la ha instituido" (Eribon, 2011, p. 33).

2. Según Eribon: "Un «sujeto» es siempre producido en y por la «subordinación» a un orden, a reglas, normas, leyes... Esto es cierto para todos los «sujetos». Ser «sujeto» y estar subordinado a un sistema de impedimentos son una sola y misma cosa. Pero aún es más cierto en el caso de «sujetos» a los que el orden social y sexual asigna un lugar «inferiorizado», como ocurre con los homosexuales" (Eribon, 2011, p. 16).

3. Como lo hace Judith Butler, en su libro Cuerpos que importan. Sobre los límites materiales y discursivos del "sexo", se utilizan los términos "fantasía" y "fantasear" para referirse a aquellas imaginaciones activas que suponen una ubicación relativa del sujeto en relación con los esquemas reguladores (Butler, 2002, p. 148). Igualmente, estos términos habrá que asociarlos inevitablemente, por lo menos para el caso de esta investigación, con la noción de Ficción que expone Barthes, en su Lección Inaugural, y entonces, con su idea de literatura: hacer ficción, acá, es fantasear, es, precisamente, hacer literatura.

4. Sobre las instituciones que reproducen el orden heteronormativo, véase el trabajo de Pierre Bourdieu, La dominación masculina, sobre todo el capítulo "Permanencias y Cambios", hacia el final del texto.

5. En este sentido, no extraña que el narrador-protagonista de esta novela plantee su autobiografía (aunque de manera siempre socarrona) como un «libro de autoayuda»y «gran herencia para las futuras generaciones». Como se verá en el análisis, el proyecto de Germán Germanóvich es, a un tiempo, individual y colectivo. 
6. El arte del performance, según el Diccionario Merriam-Webster, es: "[...] a nontraditional art form often with political or topical themes that typically features a live presentation to an audience or onlookers (as on a street) and draws on such arts as acting, poetry, music, dance, or painting."

(Diccionario Merriam-Webster, versión en línea)

7. El argumento de esta novela es, aparentemente, muy sencillo: es la historia del rechazo, separación familiar, huida y reencuentro de un gay, Germán Đ El Gado, con su padre (un reencuentro que -finalmente- terminará de nuevo en separación). Al lado de esta historia, está la historia de amor del protagonista y la historia del descubrimiento del "asunto" que su padre escondía: una hija bastarda. Si Bajtín señala a la creación de un argumento excepcional como el rasgo distintivo del método de Dostoievski, aquí se debe indicar que, para Quesada, lo excepcional está no tanto en la creación del argumento sino en la forma de contar misma, caracterizada -como ya se señaló- por un despliegue de la fantasía.

8. Sobre este aspecto, puede revisarse el trabajo de Didier Eribon, Una moral de lo minoritario, donde analiza la obra de Jean Genet. La heroificación se deberá entender como un movimiento en el que lo "paria" se vuelve material digno de ser «obra literaria», material que, además, es importante tanto para un individuo como para su comunidad. Heroificar, aquí, es hacer de lo "raro" algo «hermosamente raro».

9. Afirma Albino Chacón, en la contraportada de la novela: "En El gato de sí mismo el motivo del viaje expresa el ir y venir de los personajes nómadas de una realidad a otra, en una búsqueda y huida al mismo tiempo que, en caso del protagonista, desemboca en un viaje hacia la esquizofrenia, lugar donde lo no decible y lo no experimentable en la realidad cotidiana pareciera poder tener lugar, pero incluso aquí el discurso sigue estando fuertemente reprimido." (Contraportada de El gato de sí mismo) 
10. Al respecto de este ligamen entre la "homosexualidad" y la enfermedad psiquiátrica, puede revisarse la obra de Foucault. Eribon, además, hace un análisis de este tema en su libro Una moral de lo minoritario. Para el caso costarricense, puede revisarse el trabajo de Isabel Gamboa Barboza, El sexo como lo cura, publicado por la EUCR, en el 2009.

11. Al respecto, se puede revisar el trabajo de María Luisa Femenías, "Lectura excéntrica y cambio de paradigma: des-invisibilización de los a-priori históricos de género". En: Imprévue 1\&2. Montpellier, Edit.: CERS, 2004.

12. Aquí es importante apuntar que la razón es un “don” exclusivo de los hombres, por lo que los proscritos, todos, serán relegados, como se ha indicado, al ámbito de lo femenino.

13. Eribon, desde Foucault, habla de tres ámbitos de experiencias basados en el mundo de la sinrazón. Así, se tiene a la sexualidad en sus relaciones con la organización de la familia, a la profanación en sus relaciones con las nuevas concepciones de lo sagrado y al libertinaje, que -junto con la locura- vendrá a ser el espacio del internamiento.

14. Explica Eribon: “«Locas», «mariconas», «maricas», designan realidades «objetivas» en el mundo social y sexual, y las palabras de la estigmatización instauran y reinstauran sin cesar la «realidad» de lo que designan, cuando parecen simplemente enunciarla o desvelarla. Llamar a alguien «loca» o «marica» es enunciar la «verdad» de lo que «es». Pero este individuo sólo es lo que es porque las palabras (es decir, la historia colectiva del orden social y sexual sedimentada en el lenguaje y los fantasmas sociales que expresa) inscriben en su propia definición, y en su ser, toda la «realidad» que designan, para hacer de él un ejemplar, un espécimen de una especie particular, y le atribuyen rasgos psicológicos, prácticas, sentimientos, e incluso características físicas, que quizá no sean las suyas propias, pero que 
encajan en la definición social y fantasmal de esa categoría de personas a la que pertenece y, por lo tanto, en la suya.” (Eribon, 2004, p. 77)

15. Evidentemente, lo que se busca, en este punto, es focalizar toda la atención en esta "locura" especial, definida por la misma sexualidad del narradorprotagonista y para ella. Se pondrá, entonces, especial atención en cancelar toda la carga negativa del término para, así, activar el particular punto de vista sobre el mundo y sobre sí mismo que desarrolla el narrador de esta novela.

16. Bajtín, a la hora de analizar la historia de los géneros (con el fin de esclarecer más aún la heterogeneidad genérica y estilística en Dostoievski), plantea que la novela tiene tres raíces principales: la epopeya, la retórica y el carnaval. A partir de ellas, indica que la novela dialógica o polifónica le debe mucho a dos géneros cómico-serios, en específico: al diálogo socrático y a la sátira menipea. Evidentemente, la novela de Quesada está compenetrada por los elementos de estos subgéneros y, a partir de ellos, la valoración del héroe sólo puede ser positiva. Desde una perspectiva estrictamente monogal, el loco es un simple insensato, pero, desde la teoría carnavalesca, éste más bien innova como un sujeto de saber y, precisamente, en este punto está su carácter alterador del «orden».

17. El «humor de loca», el camp, es un tipo de juego muy propio de los espectáculos de transformistas y drag queens. El «humor de loca» resalta sobre todo- el artificio, la estilización y la parodia, elementos muy comunes, además, en la sátira menipea y en el carnaval. Afirma Eribon: "El humor de «loca» y el camp pueden describirse, ciertamente, como otras tantas estrategias de resistencia o de reapropiación de la acusación de afeminamiento, pero expresan sobre todo la creatividad, la inventiva de una cultura minoritaria, y asimismo la manera en que dicha cultura es, gracias a esta forma de ironía, la mejor crítica de sí misma y de las otras" (Eribon, 2001, p. 130) (Resaltado mío). 
18. Evidentemente, al héroe hay que entenderlo aquí simplemente como el personaje central del relato. Bajtín lo define sencillamente como una conciencia, como un sujeto con palabra; así, hay que desligar esta noción de héroe de la noción tradicional. El héroe, a partir de las afirmaciones bajtinianas, lo es en la medida en que habla de sí mismo en relación con los otros.

19. La "travestización literaria" no es sino un juego que busca desestabilizar cualquier discurso monolítico. Travestir es, a un tiempo, destruir y construir continuamente, es un gesto impugnador que, con su exposición espectacular, reafirma el artificio de cualquier «orden» y, entonces, desafía las reglas "naturales" (o, mejor, naturalizadas) que constituyen la «norma». Así las cosas, y en un texto como El gato de sí mismo, la travestización constituye toda una estrategia literaria y, claro, política, que busca cuestionar, busca minar el sentido unívoco de cualquier discurso que, como afirma Bajtín, quiera concluir al ser humano.

20. Como ya se afirmó antes, la novela El gato de sí mismo, desde la figura del narrador-protagonista, se plantea como una autobiografía. Evidentemente, hay que entender este movimiento como una estrategia de narración y no como el establecimiento de un marco genérico al texto.

21. Hablar, entonces, de esquizofrenia en relación con este héroe es calificarlo desde el punto de vista de lo que Eribon llama una «una moral de lo mayoritario», una moral que lo que busca es quitarle el sentido (objetivar) a la discursividad de esta «loca fantástica» que es Germán Germanóvich.

22. Léase la siguiente cita de la novela de Quesada: "A veces Su Majestad se enteraba de la aparición de un cadáver de muñeca, fuera por casualidad o porque el príncipe Alberto me acusaba. Entonces se ponía furioso [...]. Las muñequitas también eran la causa de discusiones entre el Rey y la Reina. Ella siempre me defendía, su argumento era la curiosidad científica, la esperanza de que el Infante Germancito se convirtiera en doctor famoso, 
especialista en ginecobstetricia, dermatología, o en última instancia una disciplina más morbosa como la medicina forense. "No", clamaba el Rey delante de mí, "el asunto no es ése. El chiquillo va que vuela para marica" " (Quesada, 2005: 50).

23. Véase la quinta acepción del término 'rechazar': "5. tr. Mostrar oposición o desprecio a una persona, grupo, comunidad, etc.” (DRAE, versión en línea)

24. Eribon utiliza este término en la medida en que entiende la discriminación contra el gay como una discriminación básicamente racial. Según explica, el "homosexual" es definido por el sistema heteronormativo como un «ser de otro mundo», y de ello se deduce su racismo, un racismo específicamente sexual.

25. Afirma Eribon: "La experiencia de la injuria es, sin duda, una de las más hondas, más traumáticas de una existencia, y la injuria repetida, la injuria temida, la injuria como referencia respecto al mundo y a los demás, produce conciencias íntimamente heridas, vulnerables, pero que pueden, como Genet también nos muestra, transfigurarse en conciencias rebeldes, desde el momento en que, a partir de lo que las palabras de odio producen (la vergüenza), les prestan otro significado (el orgullo)" (Eribon, 2004, p. 89) (Resaltado mío).

26. Afirma Eribon: "Si todo homosexual está sujeto por procesos idénticos que actúan en referencia con las mismas normas sociales y sexuales y producen en los espíritus y en los cuerpos los mismos efectos, y si, por consiguiente, un gay está siempre-ya inscrito en un colectivo que le abarca antes incluso de que le pertenezca o de que no sepa o no quiera pertenecerle, esto quiere decir que todo gesto gay, toda participación, ya fuese la más lejana, la más distante, la más secreta, en la vida gay, pone a cualquier homosexual en relación con todos los demás, y con toda la historia de la homosexualidad y de sus luchas" (Eribon, 2001, p. 89). 
Acevedo, R. 1994. "Orígenes de la nueva novela centroamericana (19681980)". La Torre (Universidad de Puerto Rico), nueva época, año VIII, no. 29 , enero-marzo.

Amoretti, M. 1992. Diccionario de términos asociados en teoría literaria. San José, C.R.: Editorial de la UCR.

Bajtín, Mijaíl. 2002. Estética de la creación verbal. Argentina: Siglo XXI. . 2003. Problemas de la poética de Dostoievski. México: Fondo de Cultura Económica. 1989. Teoría y estética de la novela. Madrid: Taurus.

Barthes, R. 2003. Placer del texto y Lección inaugural. Buenos Aires: Siglo XXI.

Bataille, Georges. 2009. El erotismo. España: Tusquets.

Butler, Judith. 2001. El género en disputa: el feminismo y la subversión de la identidad. México: Paidós.

Bourdieu, Pierre. 2004. Las reglas del arte. Argentina: Siglo XXI. 2000. La dominación masculina. Barcelona: Anagrama.

Caamaño, Virginia. 2005. "Voces marginales en "Bienvenido a tu nueva vida" de Uriel Quesada. En: Revista de Filología y Lingüística, XXXI (extraordinario): 35-42.

Calsamiglia, Helena y Tusón, Amparo. 1999. Las cosas del decir: manual de análisis del discurso. Barcelona: Ariel.

Cambell, Joseph. 1998. El héroe de las mil caras: Psicoanálisis del mito. México: Fondo de Cultura Económica. 
Chacón, Hilda. 2009. "Monstruosidades, maravillas e intersticios en Viajero que huye (2008) de Uriel Quesada". Istmo (Revista virtual de estudios literarios y culturales centroamericanos). No. 19. Disponible en: http://collaborations.denison.edu/istmo/

Chacón, Albino. 2005. "Lejos, tan lejos dentro de la narrativa de Uriel Quesada”. Presentación al libro Lejos, tan lejos, de Uriel Quesada, realizada en Costa Rica.

. 2009. "Horizontes y límites de una historia de las literaturas (A propósito de la publicación de Intersecciones y transgresiones: Propuestas para una historiografía literaria en Centroamérica)". Istmo (Revista virtual de estudios literarios y culturales centroamericanos). No. 19. Disponible en: http://collaborations.denison.edu/istmo/

Conrad, Joseph. 1908. "Il Conde”. Versión de 1908 publicada en línea por Feedbooks, Proyecto Gutenberg. Disponible en: www.feedbooks.com/book/751.pdf

Coto Rivel, Sergio. 2007. Espacios de la marginalidad y nuevas propuestas de género: la construcción del discurso homoerótico en la novela Paisaje con tumbas pintadas en rosa de José Ricardo Chaves. Tesis de Maestría en Literatura Latinoamericana. Universidad de Costa Rica.

Diccionario de la Real Academia de la Lengua. 2001. 22ª ed. Madrid. Edición en línea. Disponible en: www.rae.es

Dostoiesvki, Fedor. 2006. Memorias del subsuelo. México: Jorge a Mestas Ediciones.

Eribon, Didier. 2001. Reflexiones sobre la cuestión gay. Barcelona: Anagrama. 2004. Una moral de lo minoritario: Variaciones sobre un tema de Jean Genet. Barcelona: Anagrama. 
. 2011. "Borders, Politics and Temporality". Ponencia presentada en el Coloquio 'Sexual Nationalisms', que tuvo lugar en Ámsterdam del 26 al 29 de enero. Disponible en: http://didiereribon.blogspot.com/2011/02/politics-and-temporality.html.

Fornet-Betancourt, Raúl. 2004. Filosofar para nuestro tiempo en clave intercultural. Aachen: Concordia, Reihe Monographien/Band 37.

Foster, David. 2000. Producción cultural e identidades homoeróticas. San José: EUCR.

Gamboa B., Isabel. 2009. El sexo como lo cura. San José: Editorial de la UCR.

Grabe, Nina; Lang, Sabine; Meyer-Minnemann, Klaus (eds.). 2006. La narración paradójica: "Normas narrativas" y el principio de la "transgresión". Madrid: Iberoamericana.

Hernández, Gonzalo. 2010. "Reflexiones sobre la construcción del sujeto en la era post cartesiana". A Parte Rei. Disponible en: http://serbal.pntic.mec.es/ cmunoz11/sanjorge26.pdf

Kulawik, Krzysztof. 2009. Travestismo lingüístico: El enmascaramiento de la identidad sexual en la narrativa latinoamericana neobarroca. Madrid: Iberoamericana, Vervuert Verlag.

Kristeva, J. 1974. El texto de la novela. Barcelona: Lumen.

La Nación. 1999. "Cartas a La Nación: Un cuento en Áncora”. Cartas publicadas el 26 de mayo. .2006. "Uriel Quesada: 'Mi novela es un pastiche'”. Entrevista publicada el 1 de febrero. 
Mackenbach, Werner (editor). 2008. Intersecciones y transgresiones: propuestas para una historiografía literaria en Centroamérica. Guatemala: F\&G.

2012. (Per) Versiones de la modernidad. Literaturas, identidades y desplazamientos. Guatemala: F\&G.

Marquet, Antonio. 2011. "Las posibilidades de la errancia en Viajero que huye de Uriel Quesada. Excéntrica. Disponible en: http://www.excentricaonline.com/libros/textualidades_more.php?id=6829 _0_12_0_M88

Morillas Ventura, Enriqueta. 1999. "Identidad y literatura fantástica". Anales de Literatura Hispanoamericana, número 28, págs. 311-321.

Nietzsche, F. 2000. El gay saber o La gaya ciencia. Madrid: Espasa Calpe.

Obando, Alexander. 2008. La gruta y el arcoíris: Antología de narrativa gay/lésbica costarricense. San José: Edit. Costa Rica.

Pozuelo Yvancos, José M. 2006. De la autobiografía. Barcelona: Crítica.

Puig, Manuel. 1988. El beso de la mujer araña. Argentina: Fondo de Cultura Económica.

Quesada, U. 2005. El gato de sí mismo. San José: Edit. Costa Rica. 1985. Ese día de los temblores. San José: Editorial Costa Rica. 1990. El atardecer de los niños. San José: Editorial Costa Rica. 1996. Larga vida al deseo. San José: EUNED. 1999. Si trina la canaria. Cartago: Editorial Cultural Cartaginesa. 2004. Lejos, tan lejos. San José: Editorial Costa Rica. 
2008. Viajero que huye. San José: Editorial Uruk.

. 2004. "El escritor y la experiencia del clóset". Ponencia. Leída el 6 de mayo en Casa de América, Madrid.

Ríos Q., Verónica. 2006. “«El elefante birmano» de Uriel Quesada: Una trasgresión al imaginario nacional”. Káñina, Rev. Artes y Letras, Univ. Costa Rica XXX (2): 139-144.

Rivero G., Isabel. 2008. "Intertextualidad, polifonía y localización en investigación cualitativa”. Athenea Digital. (3), primavera 2003. Disponible en: http://antalya.uab.es/athenea/

Sarduy, Severo. 1998. "El barroco y el neobarroco". En: Obra completa. San José: Fondo de Cultura Económica.

Zavala, Magda. 1991. La nueva novela centroamericana. Estudio de las tendencias más relevantes del género a la luz de diez novelas del período 1970-1985. Tesis doctoral. Universidad Católica de Lovaina. 